\title{
La tipografía como generadora de identidad en la imagen de marca de países europeos en el s.XXI
}

\author{
Typography as a generator of identity in the \\ brand image of European countries in the XXI \\ century
}

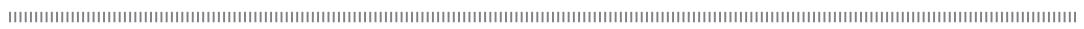

(D) Marcos Dopico Castro

Departamento de Dibujo. Universidad de Vigo, España

marcos.dopico@gmail.com

\section{Resumen}

La identidad corporativa ha sido objeto de importantes cambios en las últimas décadas. Estos cambios han alterado, entre otras cuestiones, el orden establecido de los elementos que de forma compleja definen una identidad. La preferencia por el símbolo o imagotipo, que siempre se había mantenido como eje central de la identidad, ha dado paso desde el inicio del siglo XXI a la creación de sistemas visuales variables en los cuales han entrado en juego otros elementos identificadores que, si bien ya existían, se han colocado ahora en una posición más destacada. Aquellos elementos idenficadores básicos definidos por Norberto Chaves como básicos - nombres, logotipos e imagotipos - (Chaves, 1988) han perdido poder de reconocimiento per se en una sociedad global. Uno de esos elementos que ha ganado un gran protagonismo es la tipografía. En este contexto ha surgido la tendencia de la creación de familias tipográficas "personalizadas" atendiendo a las necesidades específicas de cada una de las marcas, ocupando un lugar destacado entre estos elementos identificativos. Este artículo pretende analizar a través de casos de estudio cómo esta idea de personalización tipográfica ha sido adoptada especialmente en los últimos diez años en el rediseño de marcas de países del norte de Europa, dentro de las estrategias de reafirmación de identidad propia y vinculación con el territorio y sus tradiciones, consiguiendo una mayor proyección exterior. Los países se han visto en la necesidad de crear marcas singulares para diferenciarse de la competencia en los ámbitos del

Artículo original / Original Article

Correspondencia / Correspondence marcos.dopico@gmail.com

Financiación / Fundings Sin financiación

Recibido / Received: 30/05/2021 Aceptado / Accepted: 17/09/2021 Publicado / Published: 17/12/2021

Como citar este trabajo. How to cite this paper.

Dopico Castro, M. (2021). La tipografía como generadora de identidad en la imagen de marca de países europeos en el s.XXI. i +Diseño. Revista Internacional de Innovación, Investigación y Desarrollo en Diseño, 16. DOI: 10.24310/ Idiseno.2021.v16i.12802 
turismo, la captación de población, recursos e inversiones. En esa estrategia los creadores de marca han apuntado hacia la tipografía personalizada como herramienta diferenciadora.

Palabras clave: identidad corporativa, tipografía, marca-pais, branding, identidad.

\begin{abstract}
Corporate identity has undergone major changes in recent decades. These changes have altered, among other issues, the established order of the elements that in a complex way define an identity. Since the beginning of the 21st century, the preference for the symbol or imagotype, which had always remained as the central axis of identity, has been replaced by the creation of variable and scalable graphic systems. Other identifying elements have come into play in these systems which, although they already existed, have been placed in a more prominent position. The traditional basic elements (Chaves, 1988) such as - name, logo, imagotype - have lost the power of recognition in a global society with a gradual increase in the number of mediums, technologies and contexts in which a brand is embodied. One of those elements that has gained great prominence is typography. In this context, the trend of creating personalized typeface families has emerged, taking into account the needs of each of the brands, occupying a prominent place among these identifying elements. This article aims to analyze through case studies how custom typography has been adopted in the last ten years in the redesign of brands in countries in northern Europe, within the strategies of reaffirmation of one's own identity and connection with territorial elements with the aim of a greater projection from the difference. Countries have found it necessary to create unique brands to differentiate themselves from their neighbors in the areas of tourism, population recruitment, resources and investments. In this strategy, brand creators have pointed towards custom typography as a differentiating tool.
\end{abstract}

Key words: corporate identity, typography, branding-nation, branding, identity

\section{Introducción}

\section{La tipografía en la identidad corporativa. Entre la estandarización y la per- sonalización.}

Desde la creación y consolidación en el siglo XX de la disciplina de la identidad corporativa tal y como la conocemos hoy en día, los diseñadores han incluido entre sus estrategias el recurso de creación de tipografías corporativas personalizadas con una relación territorial con la propia marca. Estos proyectos se han creado en base a una tradición tipográfica, una funcionalidad demandada por el ciudadano o unas necesidades identitarias. Con el tiempo han establecido un vínculo inseparable con su ámbito geográfico, con su país o su ciudad y en ocasiones ha trascendido más allá de la propia marca de origen, pasando a ser reconocidas por la ciudadanía como símbolos propios. Ejemplos tempranos los podemos encontrar antes incluso de que la identidad corporativa como disciplina se consolidara, como el precedente de la identidad visual del Metro de Londres de Edward Johnston en 1916. La tipografía Johnston Underground, además de proponer un nuevo modelo humanístico de tipografía, configuró una identidad visual que ha trascendido el propio servicio público para erigirse en símbolo de identidad de una ciudad. Otro proyecto pionero fue el desarroIlado por Knud V. Engelhardt en los años 20 del s.XX para la señalética del barrio de Gentofte (Copenhagen). Una tipografía personalizada y adaptada a la señalización de sus calles adelantó nuevos caminos tipográficos y sentó las bases de la tradición 
tipográfica danesa creada por los denominados arquitectos gráficos ${ }^{1}$. Otro caso en el que la tipografía se asocia a un país es el caso de la tipografía DIN-Schrift alemana, un modelo de letra anónimo basado en las normas de estandarización DIN 1451 que desde finales del siglo XIX y a lo largo del siglo XX ha sido asociada al país germano, presente especialmente en la señalización de las carreteras, autopistas y calles.

Sin embargo, estos ejemplos singulares no fueron la norma. La ruptura radical de las vanguardias históricas con su modelo geométrico de tipografía ya había configurado una idea de la tipografía como estandarización. El diseñador suizo Max Bill definía la tipografía como: «... diseño modular, como un edificio, una cuestión de organización de piezas producidas mecánicamente como parte de una estructura» (Hollis, 2006, p. 170). Esta definición respondía a los criterios de programa gráfico sistematizado en la identidad corporativa. Si analizamos los usos en identidad corporativa de la tipografía lineal geométrica Futura² de Paul Renner, diseñada en 1926, podremos observar cómo ha sido un modelo de influencia a lo largo de la historia, hasta el punto de continuar vigente en la actualidad.

Será la llegada del Proyecto Moderno hacia mediados del siglo XX, la que impulse defi nitivamente una comunicación más global y un desarrollo del diseño hacia la estandarización, hacia un diseño más neutro y equiparable a nivel mundial independientemente del contexto geográfico. Detrás de esta idea había surgido la categoría tipográfica de las neogrotescas, cuyas máximas representantes fueron la Helvética de Max Mieddinger y la Univers de Adrian Frutiger, ambas diseñadas en torno a 1957. Estas fueron una evolución formal del precedente de las grotescas, con formas más limpias y racionales, transmitiendo una información clara por encima de las interferencias del contexto vernáculo. La tipografía, bajo esta idea de universalidad se orientó más hacia la neutralidad que defendía Wim Crouwel y que fue la idea dominante del Proyecto Moderno (Hustwit, 2007): "La tipografía debe ser neutra, no debe tener significado en sí misma. El significado debe estar en el contexto de la palabra, no en el tipo de letra».

Estas fuentes se adaptaron a la perfección al ámbito del programa corporativo, pero su éxito a nivel global obstaculizó los intentos de singularidad tipográfica y de arraigo a la identidad territorial. Tal y como afirma Lars Müller a propósito del éxito de la tipografía Helvética (Brändle et al., 2014):

Al mismo tiempo que el triunfo global del Estilo Suizo, la Helvética también se extendió pronto más allá de las fronteras del país. Después de Europa, la fuente también estuvo disponible a partir de 1963 en el gran mercado norteamericano. Diseñadores reconocidos la utilizaron en el ámbito corporativo de las identidades de empresas multinacionales -Otl Aicher para el logotipo de Lufthansa, Massimo Vignelli para American Airlines y KnoII International y FHK Henrion para British European Airlines-. Ellos fueron pioneros e

1. Los arquitectos Thorvald Bindesbøll (1846-1908), Knud V. Engelhardt (1882-1931), Gunnar Biilmann Petersen (1897-1968), Claus Achton Friis (1917-1999) y Naur Klint (1920-1978) conocidos como los arquitectos gráficos son considerados los pioneros del diseño gráfico en Dinamarca al integrar en sus proyectos arquitectura, señalización, identidad corporativa y demás disciplinas gráficas. Véase: Ejlers, Steen.(1997). Architects in danish graphic design. Scandinavian Journal of Design History, Vol. 7. 58-73.

2. Desde su creación en 1926 la tipografía Futura ha formado parte de importantes identidades corporativas a lo largo de la historia como Volkswagen, La Rinascente, Swissair, Vitra o Canal+. Véase De Rauly, A. D., Wlassikoff, M., de Rauly, A. D., \& Renner, P. (2011). Futura. Une gloire typographique. Ed. Norma.
Será la llegada del Proyecto Moderno hacia mediados del siglo XX, la que impulse definitivamente una comunicación más global y un desarrollo del diseño hacia la estandarización. 
importantes embajadores del nuevo diseño gráfico suizo, y bajo su estela Helvetica se convirtió en sinónimo de un diseño moderno, estéticamente sofisticado y versátil (P. 341).

Al éxito mundial de este modelo contribuyó el gran auge de las fundiciones tipográficas y el éxito de ventas basado en la distribución a gran escala de familias tipográficas versátiles que podían funcionar en una gran variedad de contextos.

Solo la ruptura de las normas establecidas en el periodo posmoderno en las décadas de los 80 y 90 y la irrupción de las nuevas herramientas digitales propusieron nuevos planteamientos. Tal y como afirma José María Cerezo:

Si en la primera mitad del siglo XX el diseño dominante se basaba en esquemas racionales cuyo camino genético era fácil de trazar desde los principios esenciales de la ilustración, el posmodernismo cuestiona abiertamente ese esquema de valores (Cerezo, 2017, p. 42).

La identidad corporativa, además de recuperar el arraigo al lugar, exploró la experimentación tipográfica impulsada por la llegada de la digitalización y el software de creación tipográfica, y con ello las posibilidades infinitas de personalización de cada proyecto de identidad, aferrada al lugar y al contexto.
Los caminos del revival, la deconstrucción y el layout de capas visuales socavaron la dictadura de la retícula y el pensamiento racional. La identidad corporativa, además de recuperar el arraigo al lugar, exploró la experimentación tipográfica impulsada por la llegada de la digitalización y el software de creación tipográfica, y con ello las posibilidades infinitas de personalización de cada proyecto de identidad, aferrada al lugar y al contexto. La tipografía adoptó un roll identificador singular en ocasiones superando la función del imagotipo o directamente fusionándose con él. La recuperación de la tipografía vernacular, de los rótulos amateur, la alusión al pasado tipográfico de cada lugar y la fusión de estilos jugaron un papel fundamental en los proyectos de identidad corporativa desarrollados en la Posmodernidad.

\section{La tipografía personalizada en las marcas territoriales}

En las dos últimas décadas el concepto de marca territorial se asocia al de marca-país y es definido como un conjunto de herramientas de comunicación y generación de identidades que ayudan a los países, ciudades o regiones en la captación de turismo e inversiones. Si seguimos la definición de Norberto Chaves «...la marca-país es un hecho imaginario colectivo, que no sólo puede generarse espontáneamente, sino también crearse intencionalmente a través de los operativos de construcción de marcas de lugar (place branding)»(Chaves, 2021, p. 88). Aunque los términos puedan parecer conceptos nuevos, son manejados ya desde el momento en el que un colectivo necesita proyectar una imagen de diferenciación con respecto a la competencia, tal y como nos explica Sebastián García Garrido (Garrido, 2021):

Todo poder oficial, ya sea una tribu, una jerarquía religiosa, un estado soberano u otros poderes sociales, han desarrollado siempre una estrategia protocolaria y de identidad orientada a promover una imagen competitiva de su propia entidad, dentro y fuera de su propio ámbito territorial o de sus miembros (P. 130).

Desde finales del siglo XX la disciplina del branding ha entrado de lleno en el terreno de la construcción y definición de marcas territoriales. El proceso de reestructuración industrial de Europa en los años 80 con políticas de mercado globalizadas obligó a un rediseño económico de las naciones con un aumento del sector servicios, lo que hizo resurgir en el diseño el debate en torno a las características nacionales. Los países, regiones y ayuntamientos necesitan no solo una diferenciación político-territorial-administrativa que las identifique con su población, sino que necesitan la captación de 
recursos e inversiones, además de la promoción turística y cultural como oportunidades de negocio. Wally Olins afirmaba al respecto:

En un mundo cada vez más competitivo en el que hay muchos más países que antes y donde la tecnología ofrece oportunidades de promoción notables, las naciones siguen tratando de proyectar su poder político, su influencia y su prestigio, quizá sobre todo por una cuestión de autoestima. Pero ahora, también tienen que competir por cosas materiales y cuantificables: inversión extranjera, exportaciones, turismo. (Olins, 2004, p. 177).

Hoy en día sigue existiendo en los países un anhelo de imagen singular para luchar contra la competencia, pero no pueden evitar la paradoja de la necesidad de proyectarse globalmente al tiempo que acuden a elementos locales para forjar esa imagen. Tal y como afirman Juárez et al. (2015) «El objetivo que persigue la marca-país es crear una idea simple, clara y diferenciadora que pueda ser entendida por una audiencia diversa en una gran variedad de situaciones». Esto favorece la inserción de las estrategias típicas del entorno empresarial. La marca-país se asocia cada vez más a la influencia política en el mundo y parece condicionar cuestiones como la captación de inversión extranjera, el turismo y la exportación de productos.

Los arraigos al lugar, especialmente en aquellos sitios donde existe una intención identificadora con los elementos nacionales de una rica tradición, nutren al terreno del diseño de marcas, y la tipografía personalizada enraizada en su tradición encaja a la perfección como un elemento más dentro de esa estrategia de la diferenciación con respecto a sus competidores, destacando la cultura, la tradición, la historia, el paisaje, el patrimonio gastronómico o el arquitectónico. (Dopico, 2021)

En el estudio de Satué et al. (2000, p. 202) para la exposición Signos del Siglo, Guy Julier analiza el impacto del lugar y afirma que «los diseñadores se inspiran en los mitos de lugar para construir identidades en torno a objetos», entendiendo estos como imágenes de lugar que definen culturalmente un espacio. La tipografía diseñada específicamente para atender a la construcción de una marca de lugar ha ganado protagonismo como de imagen de lugar gracias a su capacidad de identificación con el espacio geográfico, sus tradiciones y su cultura, lo que facilita crear identidad propia más coherente cuando un país trata de definir una imagen cara al exterior y cara a sus propios ciudadanos. La tipografía gana terreno aquí como uno de los operativos de construcción gráfica a los que alude Chaves.

\section{Material y método}

Para el propósito de la investigación se analizaron los casos de países del norte de Europa que en las dos últimas décadas han creado proyectos de renovación de su identidad corporativa, y en los que el diseño de una familia tipográfica personalizada forma parte esencia de esa identidad. Se descartaron aquellos casos en los que la tipografía se limitaba a la definición de una marca o logotipo y se atendió a aquellos proyectos que creaban familias tipográficas amplias que configuraban sistemas que abarcaran todo tipo de necesidades de comunicación textual en el mundo actual. Así mismo también se seleccionaron aquellos proyectos que mantenían una relación claramente identitaria con las tradiciones, la historia, la idiosincrasia de sus habitantes y la manera de entender el diseño propio, y de esta manera proyectar hacia el exterior sus singularidades. A partir de estas premisas se seleccionaron los países de Alemania, Países Bajos, Suecia, Finlandia, Noruega y País de Gales, analizando con detalle las motivaciones, las referencias y los resultados de esa relación identitaria entre la tipografía y su país de origen. 


\section{Casos de estudio}

Países Bajos. Vuelta a la unidad. El escudo de armas y la tradición tipográfica Después de la Segunda Guerra Mundial y durante las décadas posteriores, el tradicional Escudo de Armas de los Países Bajos, que había sido el símbolo de los diferentes ministerios, comenzó a ser sustituido por diferentes identidades que luchaban entre sí por destacar. El empuje del diseño gráfico en el país con una gran experiencia en identidad corporativa y la competitividad desatada entre los diferentes ministerios del gobierno creó una situación en la que cada área poseía un lenguaje visual diferente. Si bien los estudios de diseño se beneficiaron de esos encargos, lo cierto es que derivó con el tiempo en un caos gráfico y una inconsistencia visual que llegó a provocar desconfianza en el ciudadano ante esa imagen poco cohesionada. No solamente coexistían diferentes logos en áreas del gobierno, sino que cada una de ellas usaba diferentes tipografías corporativas, situación que contribuyó a aumentar ese caos además de un aumento de los costes de licencias ${ }^{3}$. Algunas de las tipografías eran tipos comerciales y otras incluso familias diseñadas a medida como los casos de la Agrofont diseñada por Luc(as) de Groot para el Ministerio de Agricultura, Naturaleza y Calidad de los Alimentos, o la OCW Talent de Marc Vleugles para el Ministerio de Educación, Cultura y Ciencia. En las siguientes décadas, especialmente en los años ochenta y noventa, este caos no hizo más que aumentar y la llegada de una crisis po-

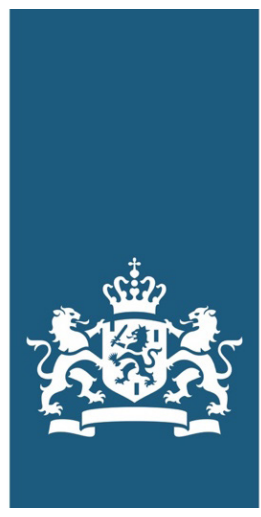

Rijksoverheid

Figura 1.

Logotipo de la identidad visual del gobierno de los Países Bajos con el escudo de armas del país y la tipografía Rijksoverheid Serif. Estudio Dumbar.

\section{Rijksov}

Figura 3.

Remates cónicos irregulares de la fuente Rijksoverheid Serif Bold.
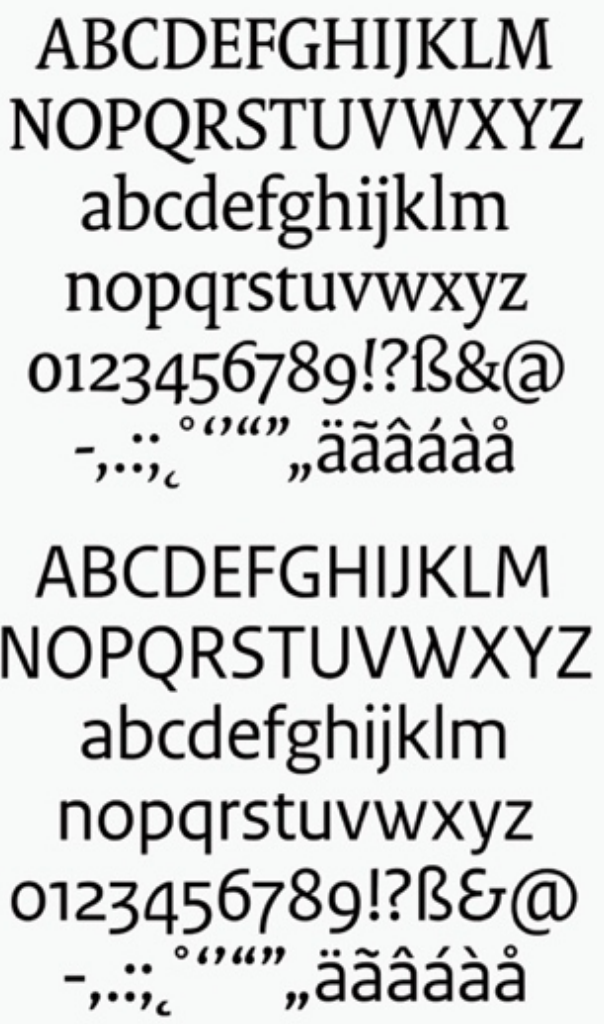

Figura 2.

Familia tipográfica Rijksoverheid Serif \& Sans de Peter Verheul.

3. Era tal la cantidad de diferentes símbolos e identidades diferentes para los ministerios y áreas del gobierno que en los estudios previos fue mostrado en una misma imagen y denominado «El muro de la vergüenza» 
lítica gubernamental en el año 2006 lo hizo más evidente. En ese momento, el gobierno demócrata cristiano de Jan Peter Balkenende tomó cartas en el asunto y comenzó a trabajar en una reunificación y homogeneización visual de los diferentes ministerios con el objetivo de optimizar los recursos y crear una imagen fuerte y cohesionada del gobierno. A este proyecto se le denominó «The 1 logo Project». Así, un año más tarde, se invitó a seis de los estudios más destacados del país (Eden, Koeweiden Postma, Total Identity, Thonik y Studio Dumbar) a desarrollar sus propuestas bajo la premisa de crear una identidad única. Studio Dumbar, fundado en 1977 por Gert Dumbar con una gran historia detrás dentro del diseño holandés, sería el elegido para desarrollar la propuesta definitiva ${ }^{4}$. El resultado fue la unificación en un logotipo síntesis del escudo de armas tradicional de los Países Bajos que incluye una triple figura del león, poniendo fin a las identidades de áreas y ministerios que había proliferado en las décadas anteriores. Pero en esta estrategia unificadora adquiere una relevancia fundamental la tipografía a medida creada para reflejar y apoyar esa identidad, adoptando una estrategia propia de las últimas décadas de uso de la tipografía como elemento reunificador, integrando y vertebrando todas las submarcas bajo un mismo paraguas.

Los Países Bajos son uno de los centros importantes en el mundo del diseño tipográfico, y son muchos los diseñadores de tipos que a lo largo de la historia han contribuido a su fama mundial. A principios de la década de los 90 el diseño de tipografías en Holan-
Figura 4.

Aplicaciones gráficas de la marca. Studio Dumbar.

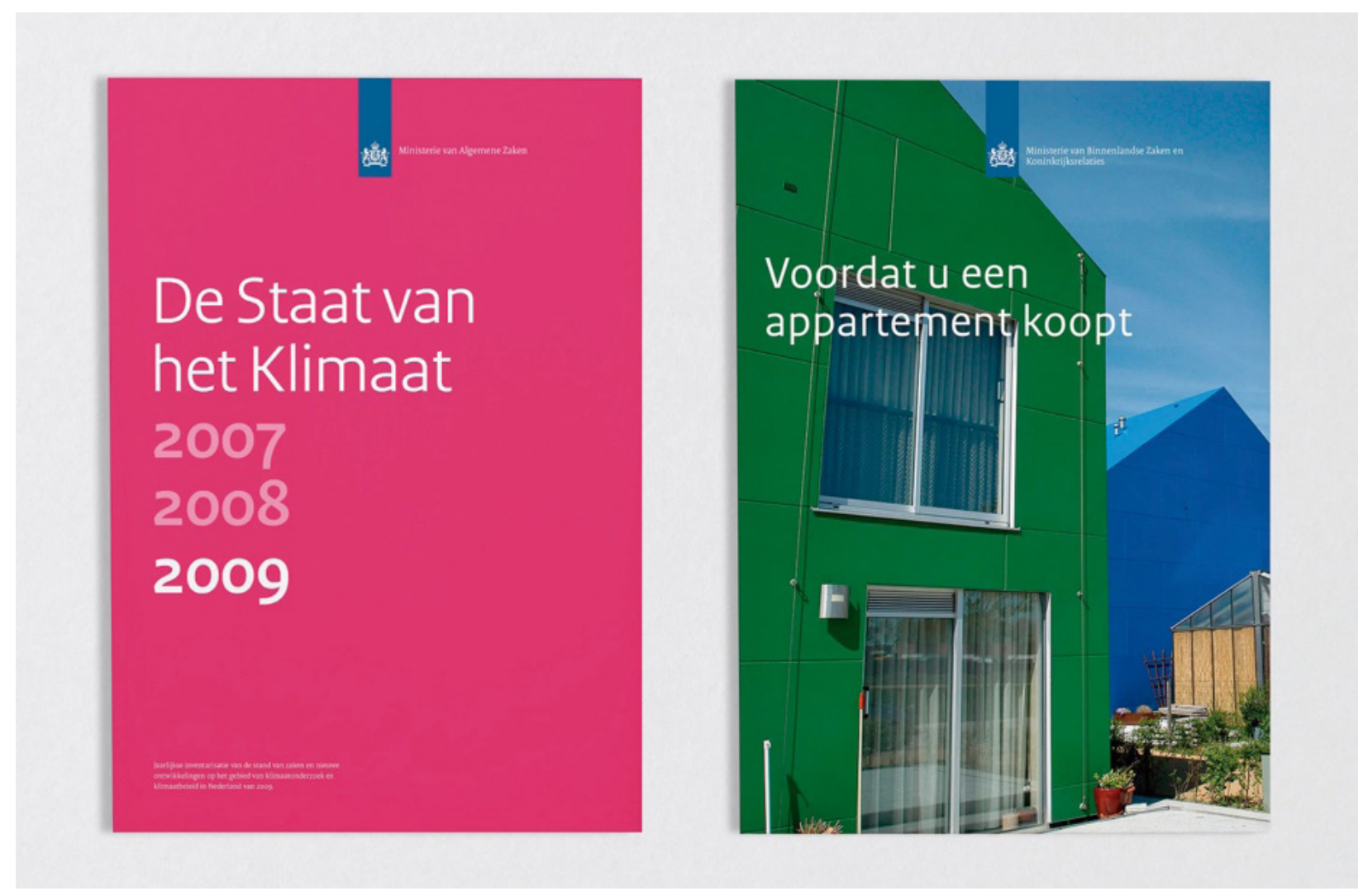

4. Véase: Molenkamp, Make y Versteegh, Martien (2010). The Style of the State. The visual identity of the Dutch government. Ministry of General Affairs. Idea books. 
da adquirió un nuevo empuje internacional gracias a los discípulos de Gerrit Noordzij, docente en la Real Academia de Bellas Artes de La Haya y una figura con una influencia clave en toda una generación de diseñadores de tipos denominada Hague types. Estos cogieron su relevo y llevaron la teoría de la forma escrita ${ }^{5}$ de su maestro a otro nivel, impulsados por la revolución del diseño digital y las nuevas herramientas de creación. Tal y como afirma el también docente Paul van der Laan:

En La Haya el diseño tipográfico no se enseña como una disciplina separada, sino que se considera parte integrante del diseño gráfico. Solo se puede juzgar el diseño de un tipo si también se usa. Este enfoque asegura que el diseño de tipografía sea más que solo formas, porque la función es igualmente importante. (Middendorp, 2018, p. 280)

De entre los discípulos de Noordzij destacan Frank E. Blokland, Peter Matthias Noordzij, Peter Verheul, Just van Rossum y Petr and Erik van Blokland. Todos ellos tienen en común una manera de entender el diseño de tipos a partir de la escritura con pluma y sus diferentes útiles trazadores, algo característico en la tradición del diseño tipográfico en los Países Bajos. Uno de ellos, Peter Verheul, profesor en la Academia de Bellas Artes desde 1991 sustituyendo a Noorzij, fue el elegido por el Studio Dumbar para el desarrollo a medida de una familia tipográfica para el proyecto de identidad del gobierno. Las premisas iniciales eran las de crear una tipografía con una alta legibilidad, conectada con la tradición del país, pero a la vez con una voz tipográfica reconocible. El diseño inicial partió de otra tipografía previamente diseñada por Verheul, la Versa. El resultado fue la familia denominada Rijksoverheid Sans and Serif6. La fuente serif se diseñó para textos de inmersión, además de logotipos e identificadores que aparecen junto al símbolo del dragón. La fuente Sans, una lineal humanística, se pensó inicialmente para titulares, pero durante el periodo de implantación de la identidad (2009-2011) surgió la necesidad de crear una sans específica para textos, ya que la original se veía demasiado fina y espaciada en textos pequeños. De esta forma la Sans se reelaboró en dos versiones, la Sans Headline y la Sans Text. La familia posee un carácter distintivo de la escuela de La Haya, con formas audaces y atrevidas, pero manteniendo al mismo tiempo una gran legibilidad y versatilidad para diferentes contextos. Verheul amplió en la versión serif los característicos remates cónicos y asimétricos que ya aparecían en la Versa, además de muchos pequeños detalles y una caja alta más estable. Toda la familia tipográfica está formada inicialmente por las fuentes serif y sans headline y text con dos pesos regular y bold con sus correspondientes cursivas. El método de diseño que parte de un mismo esqueleto para crear superfamilias con diferentes variantes sans, semisans, serif y semiserif es una práctica habitual desde los años 90 para darle mayor versatilidad en composiciones tipográficas complejas como las que requiere una identidad corporativa de un gobierno.

Todos los elementos gráficos de comunicación del estado usan esta familia, desde los denominadores de cada ministerio y área de gobierno hasta publicaciones impresas, señalización, aplicaciones web e interactivas ${ }^{7}$. Las posibilidades de personalización han permitido, además de un ahorro considerable al poseer el gobierno la licencia en exclusiva de la fuente, cubrir la mayoría de idiomas occidentales correspondientes a la codificación Latin Extended A y Griego. Más allá de cuestiones técnicas;

5. Véase Noordzij, Gerrit (2009). El trazo. Teoría de la escritura. Campgràicic.

6. Véase: Lommen, Mathieu. (2008). Letterrijk Rijksoverheid. Serif en Sans. Een letter van Peter Verheul. De Buitenkant Publishers.

7. Puede consultarse el portal de marca desarrollado en https://www.rijkshuisstijl.nl 
«Este proyecto del gobierno de los Países Bajos es un ejemplo del poder del diseño y la tipografía para la creación de una imagen unificada y de la influencia directa del diseño en la percepción de la labor política de un gobierno por parte de los ciudadanos» (Dopico, 2020).

\begin{abstract}
Alemania. Diseño para la gente
Hacia finales de la década de los 90 el gobierno alemán poseía una identidad bien definida pero tipográficamente se había tomado una serie de decisiones erráticas, cuestión que era necesario corregir en un país con una larga tradición en el diseño de tipos. Los diseñadores Lisa Eidt y Jürgen Huber habían diseñado en el año 96 una identidad que incluía el uso del símbolo del águila federal, una franja vertical con los colores de la bandera y el nombre Gobierno Federal ${ }^{8}$. Su tipografía corporativa era la Univers, posteriormente sustituida por la FF Transit en 1997. Además, también se usaban las tipografías Demos y Praxis de Gerard Unger. En 2011, bajo la dirección de diseño de Metadesign, se encarga la familia corporativa personalizada Bundes Serif \& Sans al estudio Supertype, sin embargo, sigue sin usarse en el logotipo. La agencia Adlerschmidt propuso en 2017 ampliar la familia tipografica Bundes con una versión condensada con el objetivo de usarla en el logotipo y unificar la identidad de forma más coherente.
\end{abstract}

Las premisas de este proyecto de familia tipográfica eran claras. Debía cubrir todas las comunicaciones emitidas por el gobierno y sus ministerios, tanto en soportes online como físicos, a nivel nacional e internacional. El desafío era dirigirse a un público objetivo general muy heterogéneo que abarcaba toda la población de ciudadanos que entrasen en contacto con la información emitida por el gobierno alemán, de todos los orígenes sociales y culturales. La palabra escrita, tanto en una publicación impresa, una valla publicitaria o una página web, debía ser accesible y legible. Tal y como afirman sus creadores Jürgen Huber y Martin Wenzel (Huber \& Wenzell, 2011): «Aunque estábamos acostumbrados a trabajar en proyectos como estos para corporaciones, ahora se nos pidió que diseñáramos "para la gente" ". Los diseñadores optaron por

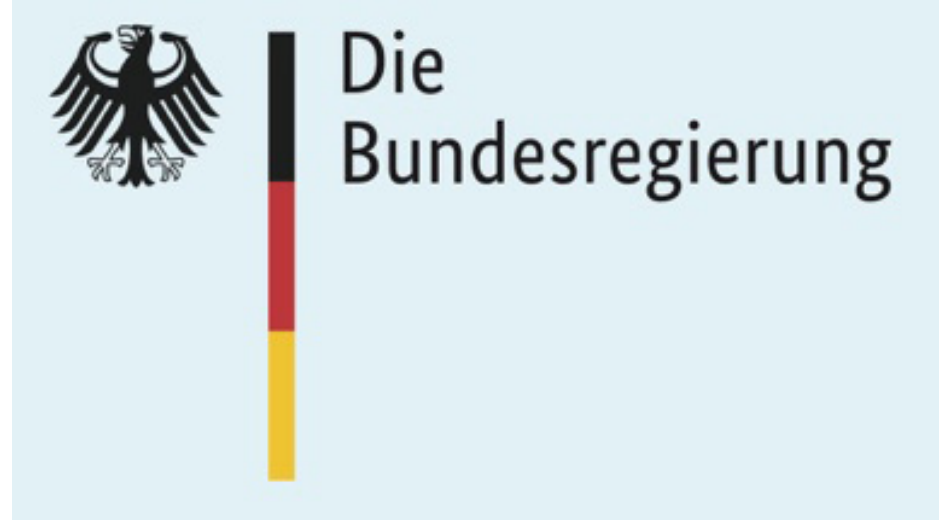

Figura 5. Identidad del Gobierno Alemán. Tipografía Bundes Sans Condensed.
Bundes Sans Bold

ABCDEFGHIJKLMNOPQRSTUVWXYZ abcdefghijklmnopqrstuvwxyz 0123456789

Bundes Sans Regular

ABCDEFGHIJKLMNOPQRSTUVWXYZ abcdefghijklmnopqrstuvwxyz 0123456789

Bundes Serif Regular ABCDEFGHIJKLMNOPQRSTUVWXYZ abcdefghijklmnopqrstuvwxyz 0123456789

8. Pueden consultarse el portal de marca en https://styleguide.bundesregierung.de/sg-de

Figura 6.

Familia Bundes Sans \& Serif. Fundición Supertype. 
Figura 7.

Referentes formales en el diseño de la familia Bundes Sans \& Serif.
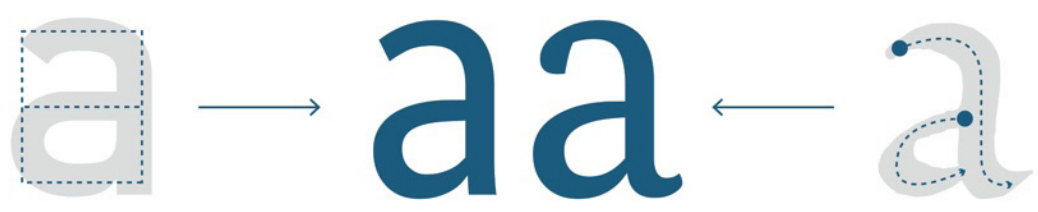

DIN 1451

Construída/Estática
Bundes Sans \& Serif
Escritura manual Dinamismo

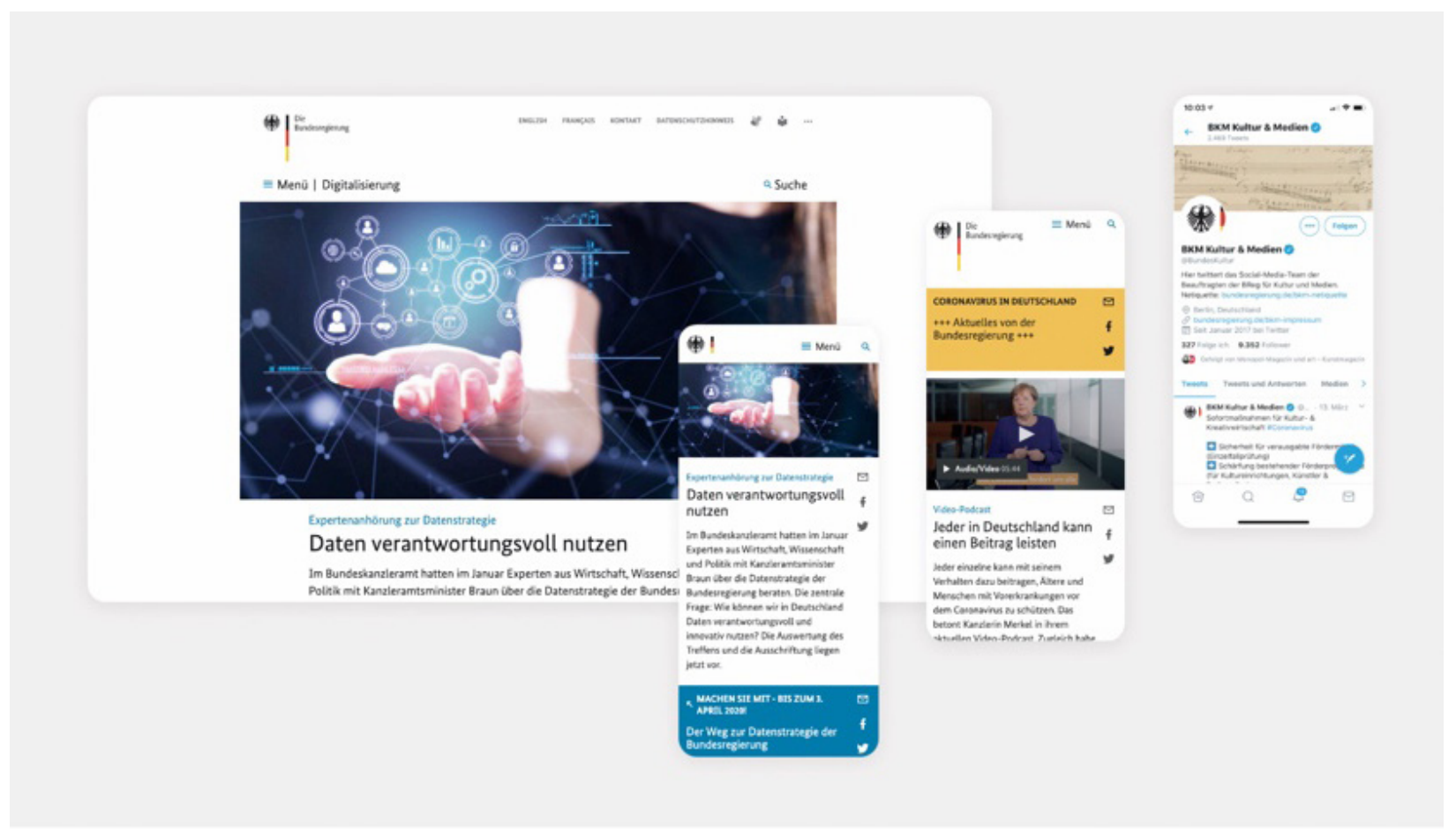

Figura 8.

Aplicaciones Web y Apps. Portal de marca. eliminar los rasgos extravagantes y los elementos decorativos. La idea era transmitir una imparcialidad amigable, aunque fuese a costa de no mostrar demasiada personalidad ya que en este caso el objetivo no era destacar sino cumplir una función pública.

La familia Bundes plantea un consenso entre las tipografías de la norma DIN y las Humanistas del s. XV, entre un planteamiento que irradia objetividad e ingeniería y otro que bebe de las fuentes de la escritura manual con formas abiertas y dinámicas. Dicho de otra forma, entre la razón y la emoción. En términos de accesibilidad, la familia posee las características formales que normalmente se suelen considerar como óptimas. Establece una diferenciación entre la altura de los ascendentes y la altura de mayúsculas, lo que evita conflictos de identificación entre varios caracteres. Posee una generosa altura $x$, lo que favorece su legibilidad en tamaños pequeños. Enfatiza la forma circular del punto de i y j, además de los signos de puntuación para una mejor percepción visual de los mismos. También establece una diferenciación formal entre caracteres conflictivos que pueden llegar a confundirse como la I, I y 1 . Sus contraformas son amplias y los terminales son abiertos. Evita las formas en espejo de los caracteres b, d, p y q de modo que diferencia la forma de cada uno de ellos para favorecer su legibilidad. 
La familia tipográfica al completo cumple con la norma de legibilidad DIN 1450, modificada en el año 2013 a petición de la Asociación Alemana para ciegos y discapacitados visuales DBSV. Aunque no es una norma de obligado cumplimiento, y muchos contextos como el diseño editorial han perfilado sus estándares de calidad a lo largo de la experiencia de los años, en otros contextos más críticos como aquellos relativos a la salud, seguridad, transporte y orientación puede suponer una ayuda, de ahí la especial atención que ha prestado el gobierno alemán en este aspecto del proyecto de identidad. Hay que recordar que las normas DIN ${ }^{10}$ surgen en Alemania en 1917 como un sistema de normalización inicialmente industrial para posteriormente atender a muchos otros aspectos, por lo que en el contexto y la tradición alemana es un asunto muy relevante.

\section{Suecia. La bandera y la tradición del diseño}

Las instituciones gubernamentales han tenido que adaptarse en los últimos años, al igual que cualquier otra identidad corporativa, al desafío de la comunicación multilingüe y sus necesarias variaciones formales. Los elementos básicos de identidad, pensados como elementos inamovibles, se han visto obligados en los últimos años a replantearse como formas flexibles y líquidas buscando estrategias para adaptarse a las circunstancias cambiantes y a multitud de contextos a los que se tiene que adaptar una marca. Es el caso de la marca del gobierno sueco, que en 2013 encargó a la agencia Söderhavet a través de la NSU (Consejo para la promoción de Suecia) el desarrollo de una nueva identidad ${ }^{11}$ de país. El trabajo inicial partió de la búsqueda de los símbolos que podían unir a sus habitantes, que fuesen capaces de reflejar el alma y el corazón de su país. El lugar de acudir a los símbolos más tradicionales como los escudos de armas o las coronas características del país nórdico, los creadores optaron por un elemento sencillo como la bandera sueca como el sistema visual más reconocible como símbolo de la nación y el que más había persistido en el tiempo. Así plantearon un sistema visual basado en la bandera de Suecia, los colores nacionales y una tipografía creada a medida en la fundición tipográfica So-Type. Este sistema propone una estructura de marca escalable, con un símbolo común de la bandera y un denominador que identifica a Suecia en su idioma nativo (Sverige) y que en función de las necesidades se traduce a diferentes idiomas del mundo. Este planteamiento atiende a un impulso internacional y usa la tipografía personalizada como elemento unificador e identitario.

Más allá del uso de la tipografía y los elementos básicos de la identidad de una forma variable y escalable, esta estrategia pretende crear un sentimiento de orgullo e identificación entre los ciudadanos y su lengua materna. Pero más allá del propio mensaje esta identidad mira hacia la tradición del diseño en el país para conseguir

9. Puede consultarse la última versión de la normativa DIN 1450 en https://www.beuth.de/de/ norm/din-1450/170093157?SearchID=494580178

10. El Deutsches Institut für Normung DIN se funda en Berlín en el año 1917 con el nombre de NADI Comité de Normalización de la Industria Alemana, y en 1926 pasa a denominarse ADN Comité de Normalización Alemán con el objetivo de reflejar que la organización pasaba a ocuparse de muchos otros campos y no solo el industrial. Finalmente, en 1975 pasaría a denominarse DIN, siendo reconocido como el organismo oficial de normas nacionales alemanas, aunque muchas de ellas han sido adoptadas por otros países en Europa.

11. Puede consultarse el portal de marca https://identity.sweden.se/en 

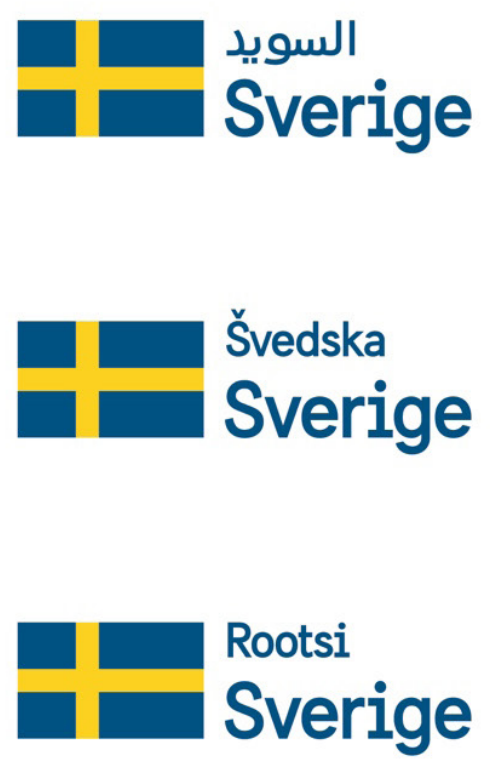

Figura 9.

Logotipo del gobierno de Suecia. Agencia Söderhavet.

Figura 10.

Diferentes variaciones de idiomas del logotipo. Agencia Söderhavet.
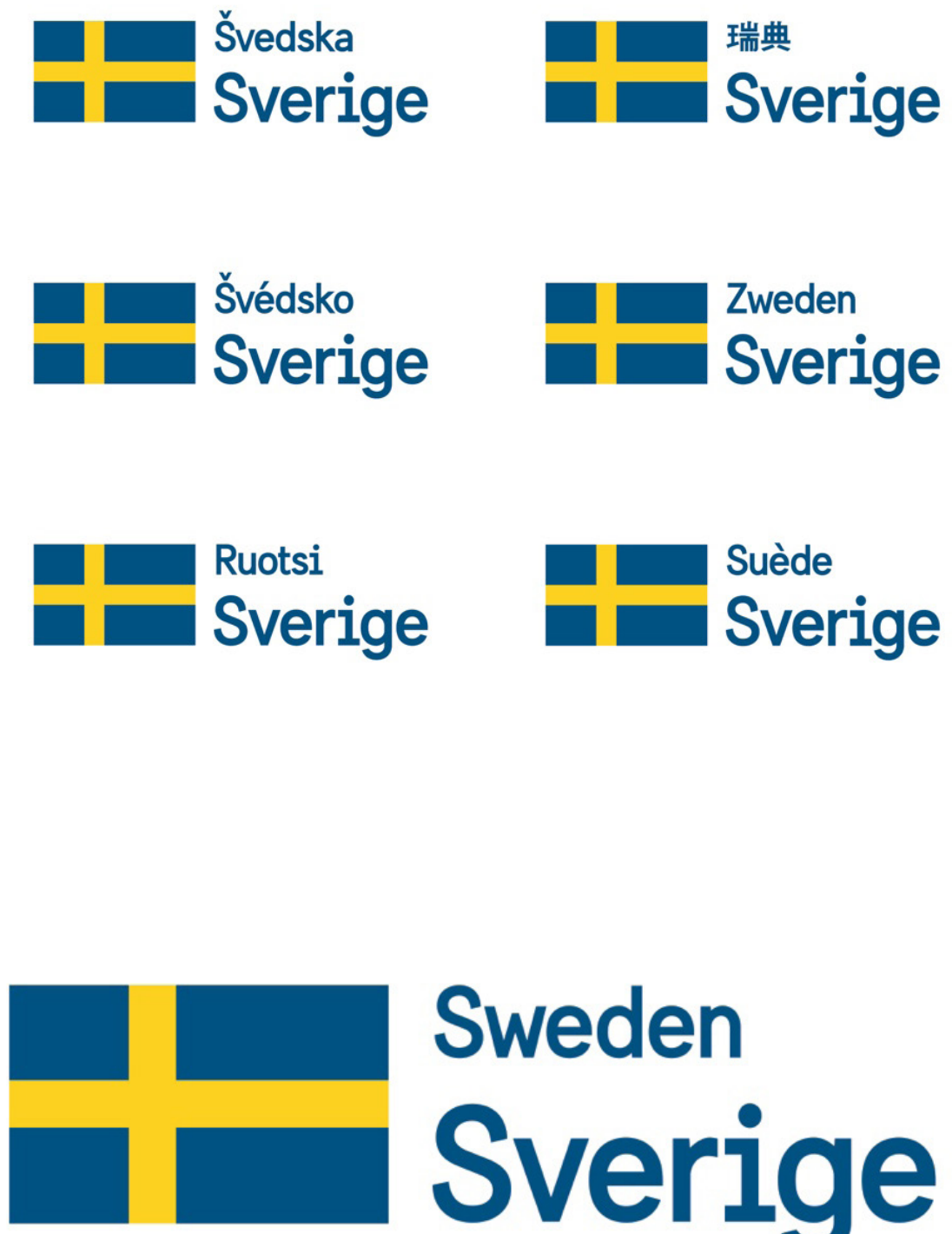

Sweden

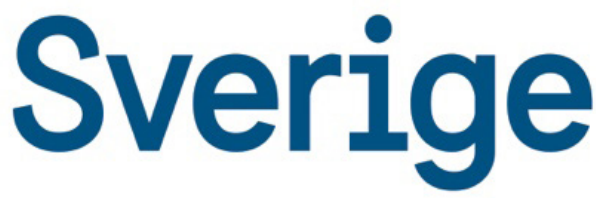

esa expresión visual única aplicable a todas las áreas de gobierno. Se trata de una tipografía de carácter geométrico y modular, con cierto aspecto mecánico. Sus autores Stefan Hattenbach y Jesper Robin buscaron ese vínculo emocional con la tradición del diseño (Söderhavet, 2014). "Decidimos optar por un diseño inspirado en los letreros de las calles suecas clásicas, con acentos combinados de tipo mono y sans-serif que muestran claramente una herencia escandinava».

La cobertura de idiomas de la tipografía abarca más de 50 idiomas para cumplir las premisas del proyecto, comunicar la imagen de la marca Suecia en un espectro de idiomas lo más amplio posible y que esa imagen fuese homogénea. Sweeden Sans está disponible en los pesos Bold, Semibold, Regular y Book. 
든

Brand Typeface

Sweden Sans Bold

Sweden Sans Semibold

Sweden Sans Regular

Sweden Sans Book

Figura 11

Tipografía corporativa del Gobierno de Suecia. Fundición So-Type.
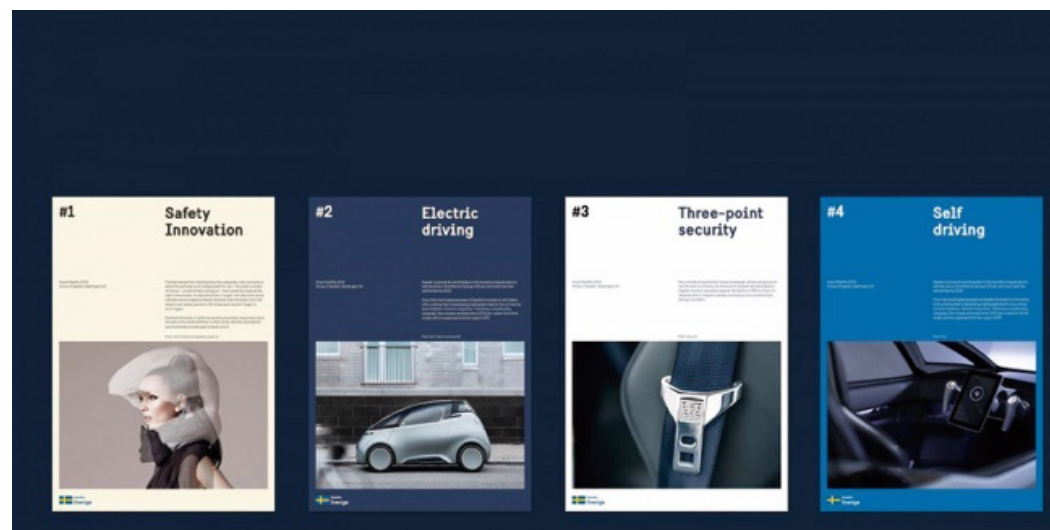

$=$

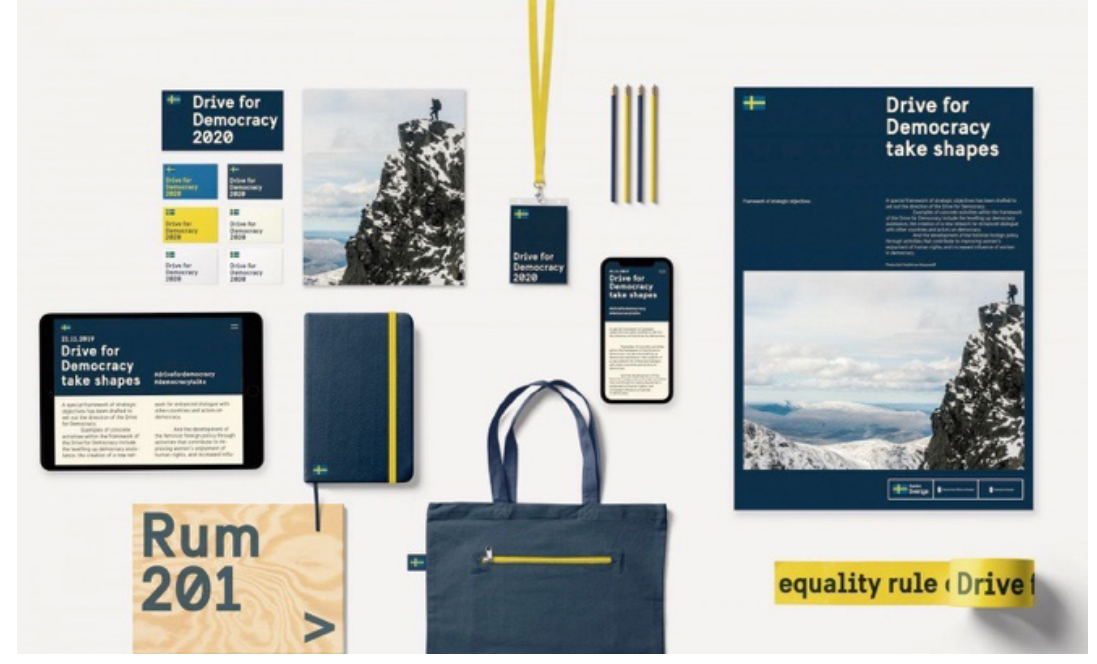

Figura 12

Ejemplos de aplicaciones de la identidad corporativa del Gobierno de Suecia. Portal de marca https:// identity.sweden.se 
Figura 13.

Elementos de la identidad corporativa del Gobierno de Finlandia. Hasan \& Partners. Portal de marca https://toolbox.finland.fil brand-identity-guidelines/.

Figura 14.

Variaciones de símbolo y logotipo. Hasan \& Partners.

\section{Finlandia. Filosofía de vida y diseño}

Finlandia, al igual que sus vecinos escandinavos, es un país orgulloso de su cultura y sus tradiciones. En el año 2015 su gobierno decide crear una identidad visual ${ }^{12}$ que atendiese a esos valores tradicionales junto a sus logros más actuales. En el proyecto cobra especial protagonismo el concepto $\operatorname{sisu}^{13}$, actitud honesta y resiliente arraigada en la sociedad finlandesa y que alude a la perseverancia y fuerza necesaria para superar dificultades en situaciones extremas y desafiantes. Esta actitud ha jugado un papel fundamental en la cohesión social del pueblo finlandés en su proceso de creación de una entidad propia en sus procesos de independencia. El estudio de diseño Hasan and Partners fue el encargado de transmitir esa honestidad del sisu, y al igual que sus vecinos suecos la identidad se basa en la bandera finlandesa con su color azul característico y en una familia tipográfica lineal de corte geométrico-industrial. Este carácter industrial pretende representar su industria, sus logros sociales, políticos y económicos del último siglo y a su apuesta por la sostenibilidad en un país con una naturaleza y recursos privilegiados. Estos esfuerzos de su sociedad han colocado a Finlandia en lo más alto en muchos aspectos a nivel mundial. Su lema «realiable, quirkly, sympatethic» (fiable, peculiar, simpático) refleja la imagen hacia el exterior que pretende emitir. La tipografía personalizada denominada Finlandica fue creada por los diseñadores
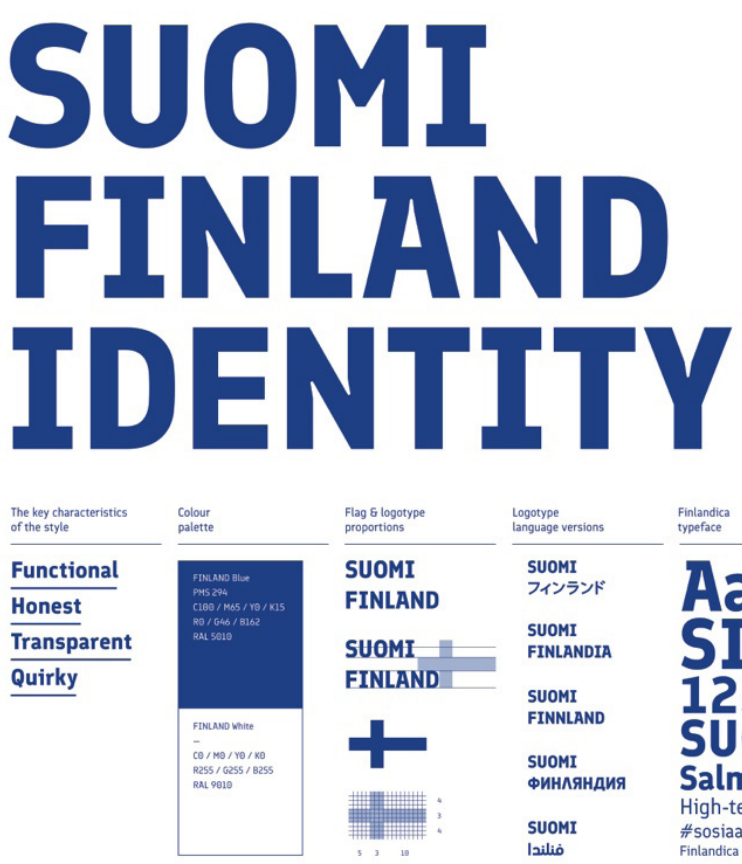

Flag \& logotype
proportions

SUOMI FINLAND

SUOMI FINLAND
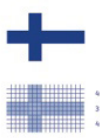

\begin{tabular}{l}
$\begin{array}{l}\text { Logotype } \\
\text { language versions }\end{array}$ \\
\hline SUOMI \\
フインラント \\
SUOMI \\
FINLANDIA \\
SUOMI \\
FINNLAND \\
SUOMI \\
ФИНイЯндИЯ \\
SUоMI
\end{tabular}

فîلندا
Finlandica
typeface

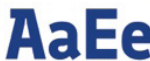
SISU 12345 SUOMI Salmiakki

High-technology \#sosiaalinenmedia
Finlandica Bold \& Regular

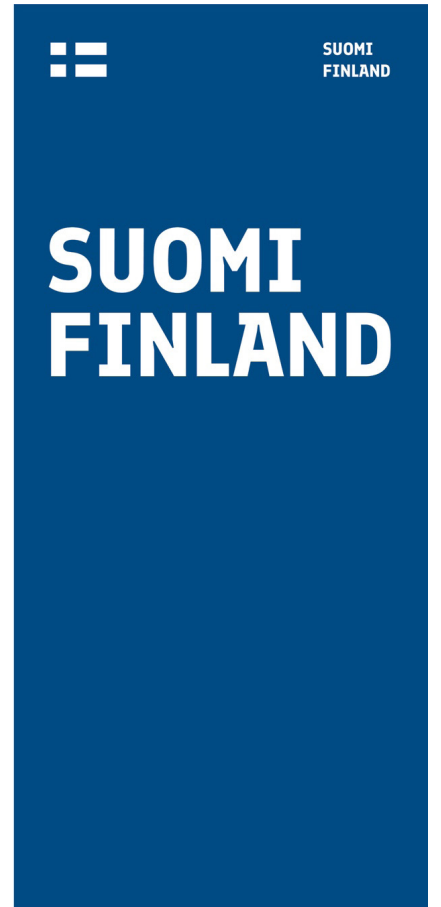

12. Puede consultarse su portal de marca https://toolbox.finland.fi/brand-identity-guidelines/

13. El término sisu significa literalmente entrañas o intestinos en finlandés. Pero su significado real tiene que ver con la fuerza interior que el ser humano desarrolla en situaciones extremas, con la energía que se desarrolla con determinación ante adversidades que parecen infranqueables. Aunque inicialmente la filosofía luterana la consideraba una característica negativa, asociada a alguien que no sigue las órdenes establecidas, durante el periodo de construcción de una nueva nación como la finlandesa después de su independencia de Rusia en 1917 fue valorada como una cualidad positiva y fundamental para su cohesión social. 
Jaakko Soumalainen, Niklas Ekholm y Joho Hiilvirta de la fundición Helsinki Type Studios $^{14}$. Sus creadores la definen como una tipografía funcional y limpia, con pequeños detalles peculiares. Tal y como reza en la información del propio archivo opentype: «Finlandica encarna la herencia tipográfica de la industria en temperaturas bajo cero. Estética avanzada para una economía avanzada: utilidad combinada con fuerte personalidad». Esos detalles peculiares se los confiere en parte sus trampas de tinta ${ }^{15}$ que la hacen funcional en tamaños pequeños, si bien este recurso con la mejora de las tecnologías de impresión y sus soportes ha derivado hacia una intención estética y está más pensado para ofrecer una fuerte personalidad en tamaños display. Su aspecto sin lugar a dudas posee buena parte de las características que se pueden encontrar en el denominado diseño tipográfico nórdico, desarrollado en ese entorno geográfico y con particularidades comunes. El diseño limpio, funcional y directo que siempre ha caracterizado a estos países más al norte de Europa tiene su reflejo también en la tipografía. Se buscan formas neutras, estructuradas y modulares, pero con un aspecto amable. Normalmente son tipografías de palo seco lineales con un contraste mínimo o nulo entre sus trazos horizontales y verticales. Sus contraformas son abiertas, su altura $x$ es amplia y sus trazos ascendentes y descendentes cortos derivados de su influencia de la señalética tradicional de sus calles, disciplina que necesita de un interlineado muy
Figura 15.

Tipografía corporativa Finlándica para el Gobierno de Finlandia. Fundición Helsinky Type Studios.

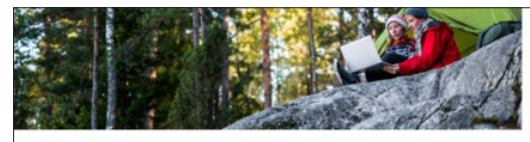

Welcome to
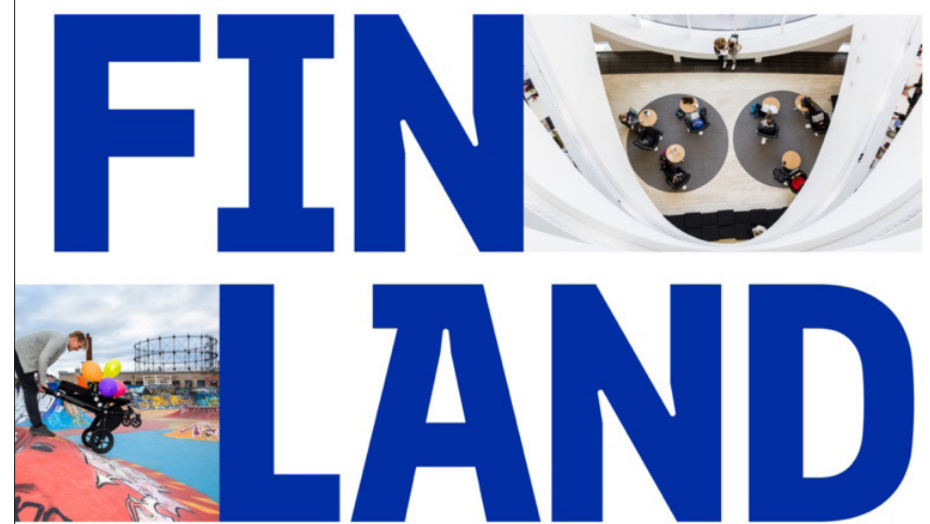

SUOMI | FINLAND | Identity guide
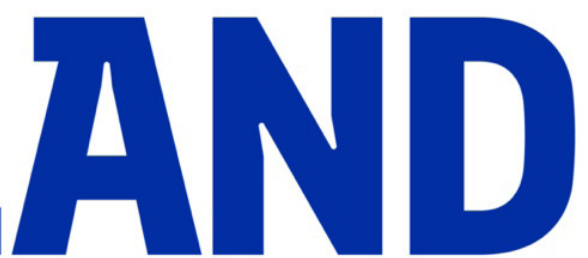

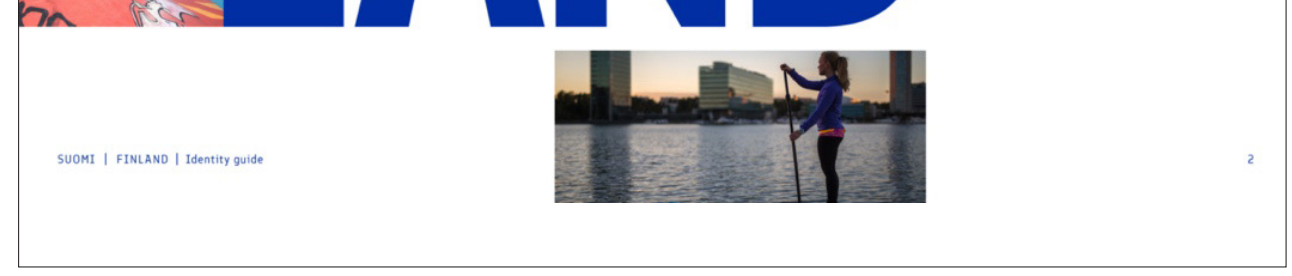

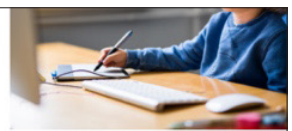

Join the team

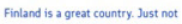
enough people know it yet . We have to increase amareness of Finland to make mebsite offers a variety of ready-made presentations, itmagess, videos, and good nord about Finland. This guide tells you how to use hise

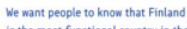
cintry in the motld. There are a lot of great facts and figures to prove this. We are among the best countries in different rankings from cosed the

14. www.helsinkitypestudios.com

15. Las trampas de tinta o Ink traps se refiere a las modificaciones realizadas en las tipografías diseñadas para la impresión en tamaños pequeños. Se trata de pequeños huecos creados en las esquinas o ángulos de los glifos para permitir una expansión de la tinta en la impresión más allá de su diseño original y de esta manera mantener la forma de la tipografía en su contorno por compensación. Habitualmente las tipografías con trampas de tinta son aquellas diseñadas para la impresión de periódicos cuyo tipo de papel ofrece una expansión mayor de la tinta a la hora de la impresión. 


\section{Finlandica Regular \\ AaBbCcDdEdFfGgHhIiJjKkLIMmNnOo PpQqRrSsTtUuVvWwXxYyZzÅåÄäÖö!?* 1234567890 " $\frac{\pi}{\pi} \% / \mid \backslash[] @()=;:$,}

Finlandica Bold

\section{AaBbCcDdEdFfGgHhIiJjKkLLMmNnOo PpQqRrSsTtUuVvWwXxYyZzÅåÄäöö!?* 1234567890"\#€\%\&/|I[]@()=;:, .}

Figura 16.

Elementos de la identidad corporativa del Gobierno de Finlandia. Hasan \& Partners. Portal de marca https://toolbox.finland.fi/ brand-identity-guidelines/. apretado. Su geometría se aleja de los principios radicales de la vanguardia histórica para acercarse a las formas cuadradas modulares ligeramente condensadas. Sus formas se alejan de la tradición ortodoxa de las imprentas ya que es una zona geográfica donde la tipografía fue creada y ejecutada por arquitectos, dibujantes, ilustradores y artesanos con técnicas basadas en la pintura, el estarcido o el esmalte alejadas de la impresión tradicional de libros. Sin duda estos condicionantes han influido en su forma reconocible frente a sus coetáneas europeas más al sur.

En coherencia con los valores que pretende transmitir el país, la tipografía Finlandica no es de uso restringido, sino que es accesible bajo licencia SLI Open Font Licence en la plataforma GitHub ${ }^{16}$. Si nos trasladamos al mundo físico sigue el concepto de "jokamiehenoikeus» que, en términos de uso y disfrute de la naturaleza, permite el acceso público a tierras, lagos o ríos de propiedad pública o privada para el ocio. En países como Finlandia, Islandia, Noruega, o Suecia está tan arraigado en la sociedad como derecho básico que no ha sido necesario legislarlo hasta la actualidad. Este derecho no incluye ninguna explotación económica de los recursos, como la caza o la tala de árboles, y conlleva la responsabilidad de no dañar, perturbar y conservar la naturaleza. Siguiendo esta lógica, la licencia OFL bajo la cual se distribuye la tipografía permite utilizarla, estudiarla, modificarla y redistribuirla libremente siempre que no se venda por sí misma.

\section{Noruega: Turismo e industria}

Noruega es otro de los países escandinavos que ha abordado recientemente el proyecto de creación de una marca como país en base a una apuesta de país sostenible con soluciones innovadoras. En 2017 el gobierno de la primera ministra Erna Solberg plantea la necesidad de la creación de la marca Noruega, especialmente de cara al exterior, atendiendo al turismo y las inversiones en la industria. Esta marca debía además reflejar y transmitir la imagen de un país que apuesta por la tecnología verde y la sostenibilidad. Debía representar además el espíritu de su gente, diversa, inclusiva y con visión de futuro.

16. https://github.com/HelsinkiTypeStudio/Finlandica 


\section{패늘 Norway}

Aa Bb Cc Dd Ee Ff Gg Hh li

Jj Kk LI Mm Nn Oo Pp Qq

Rr Ss Tt Uu Vv Ww Xx Yy Zz

Bß ÆEæ Øø Åå

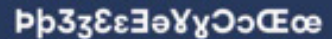

$0123456789, .-[" \# \$ \% \& /()=$ ?'

Aa Bb Cc Dd Ee Ff Gg Hh li

Jj Kk LI Mm Nn Oo Pp Qq

Rr Ss Tt Uu Vv Ww Xx Yy Zz

Bß AEæ Øø Åå

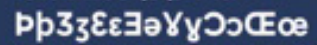

$0123456789, .-! " \# \$ \% /()=$ ?'

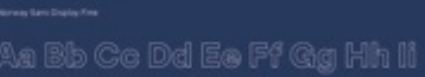

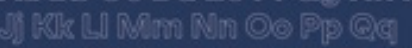

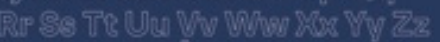

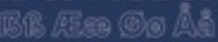

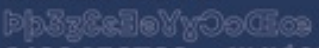 \\ (0) 2345678909}

Aa Bb Cc Dd Ee Ff Gg Hh li Jj Kk LI Mm Nn Oo Pp Qq

Rr Ss Tt Uu Vv Ww Xx Yy Zz

ßß Ææøø Åå

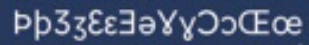

$0123456789, . .-! " \# \$ \& /()=$ ?'
Figura 17.

Logotipo de la identidad visual de Noruega. Scandinavian Design Group.

Figura 18.

Tipografía corporativa Norway Sans de la marca Noruega.

Fundición Tinny Type Co.
Aa Bb Cc Dd Ee Ff Gg Hh li

Jj Kk LI Mm Nn Oo Pp Qq

Rr Ss Tt Uu $V_{v} W_{w} X x Y_{y} Z z$

ßß ÆЕæ Øø Åå

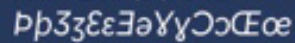

$0123456789,,-$ !'”\#\%E/()=?'

\section{North of the ordinary 맽든}

El estudio de diseño Scandinavian Design Group planteó un sistema modular ${ }^{17}$ a partir de la articulación de la propia bandera del país. Las líneas y colores de la bandera se transforman en gráficos que generan infinitas variaciones como símbolo de una nación que celebra la individualidad, pero a la vez es más fuerte unida. La identidad añade también un conjunto de ilustraciones e iconos a medida, y por supuesto una tipografía personalizada. Todos estos elementos siguen una misma línea gráfica coherente creando un lenguaje visual diverso pero reconocible.

El proyecto abarca múltiples soportes por lo que las reglas de uso de la tipografía debían ser simples y con una amplia cobertura de idiomas. Para facilitar la unificación del mensaje, la tipografía Norway Sans posee las versiones Display, Display Fine (con línea de contorno) y Text, con los pesos Bold y Regular. Fue creada por Robin Mientjes

17. Puede consultarse el portal de marca https://www.brandnorway.no/

\section{Norway}

Figura 19.

Aspectos constructivos de la tipografía Norway Sans.

Figura 20.

Aplicaciones de la tipografía Norway Sans. 
de la fundición tipográfica Tinny Type Co. bajo en encargo del estudio Scandinavian Design Group. El estilo display atiende tanto a la parte más gráfica como a la parte tipográfica, con una combinación de formas curvas y rectas de manera visible en tamaños grandes. Junto a las versiones display se diseñó la versión para texto que, siguiendo el mismo patrón de diseño y sin perder su estilo, está optimizada para tamaños pequeños, textos de inmersión, soportes web, video y aplicaciones interactivas. El soporte de lenguas abarca todos los idiomas de los países donde Noruega tiene misión diplomática más todos los idiomas con codificación Latin.

\section{País de Gales. Recuperación de una lengua con rasgos distintivos propios.}

Los rasgos lingüísticos propios de un idioma que presentan caracteres diferenciados, signos diacríticos, ligaduras o glifos únicos también han sido objeto de atención en el diseño tipográfico. La prevalencia o repetición de ciertas combinaciones de glifos en determinados idiomas ha provocado que una familia tipográfica en su diseño pueda atender a un lenguaje preferente de uso, ya que una composición de texto puede lucir un aspecto diferente en un idioma u en otro. En ocasiones, el diseño ha prestado atención a estas peculiaridades para promover un sentido del lugar y una identidad propia a través de la tipografía. Es el caso del País de Gales que en el año 2015 a través del Departamento de Turismo del gobierno encargó al estudio Smörgåsbord ${ }^{18}$ con sedes en Amsterdam y Cardiff y al consultor Joseph Burnin una renovación de su identidad visual ${ }^{19}$ como país. Su elemento central está basado en uno de sus iconos, la figura del tradicional Y Ddraig Goch ${ }^{20}$ o Welsh Dragon (dragón galés), con formas simplificadas y adaptadas a los nuevos soportes, tratando de establecer un vínculo con la bandera nacional. Pero además de este elemento era necesario reforzar ese sentido del lugar y se diseñó para ello una tipografía corporativa personalizada que prioriza los rasgos lingüísticos del idioma galés. Tal y como nos indican los autores, la idea era «crear un tipo de letra único que encarne el espíritu galés con capacidad de comunicar un sentido del lugar sin el apoyo de la gráfica».

Figura 21.

Logotipo del dragón galés de la marca País de Gales. Estudio Smörgåsbord.

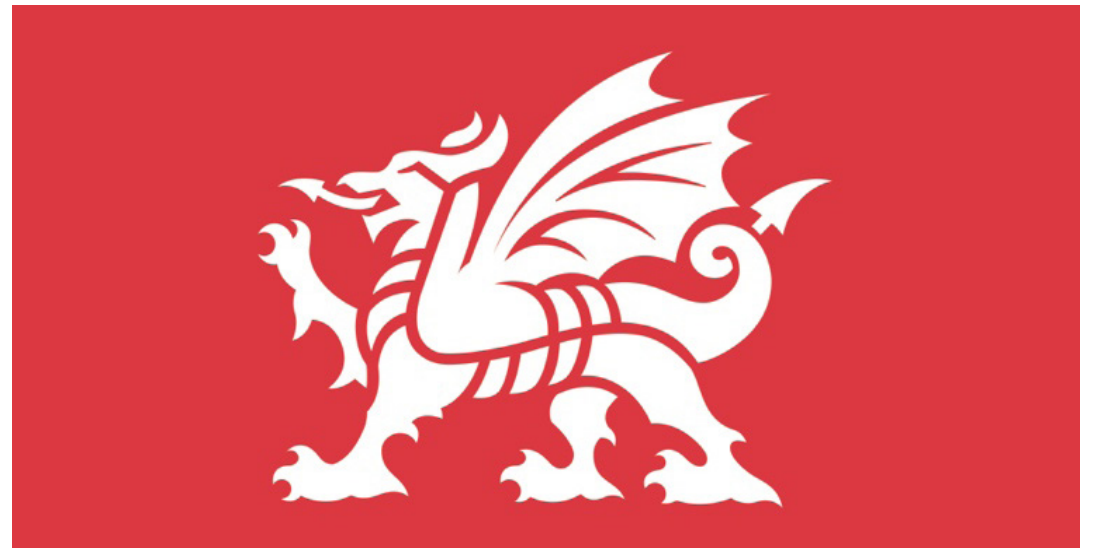

18. https://www.smorgasbordstudio.com/work/cymru-wales-branding

19. Puede consultase en portal de marca en https://assets.wales.com/

20. Y Ddraig Goch, que significa dragón rojo, es un símbolo heráldico que aparece en la bandera nacional de Gales. Aunque sus primeras referencias escritas a su existencia datan del año 829 D.C., popularmente se reconoce como el estandarte de la batalla del Rey Arturo y otros líderes celtas antiguos. El Dragón Rojo se considera un símbolo de Gales y es usado en la actualidad por numerosas instituciones públicas y privadas del país. 


\section{Cymru Wales Sans AaBbCCDdEeffGgHhli JjKkLLMmNnOoPpQqRr SsTtUuVvWwXxYyZz LCCFFThthffchdo 123456789!?€q}

Figura 22.

Tipografía Cymru Wales.

Fundición Colophon Typefoundry.

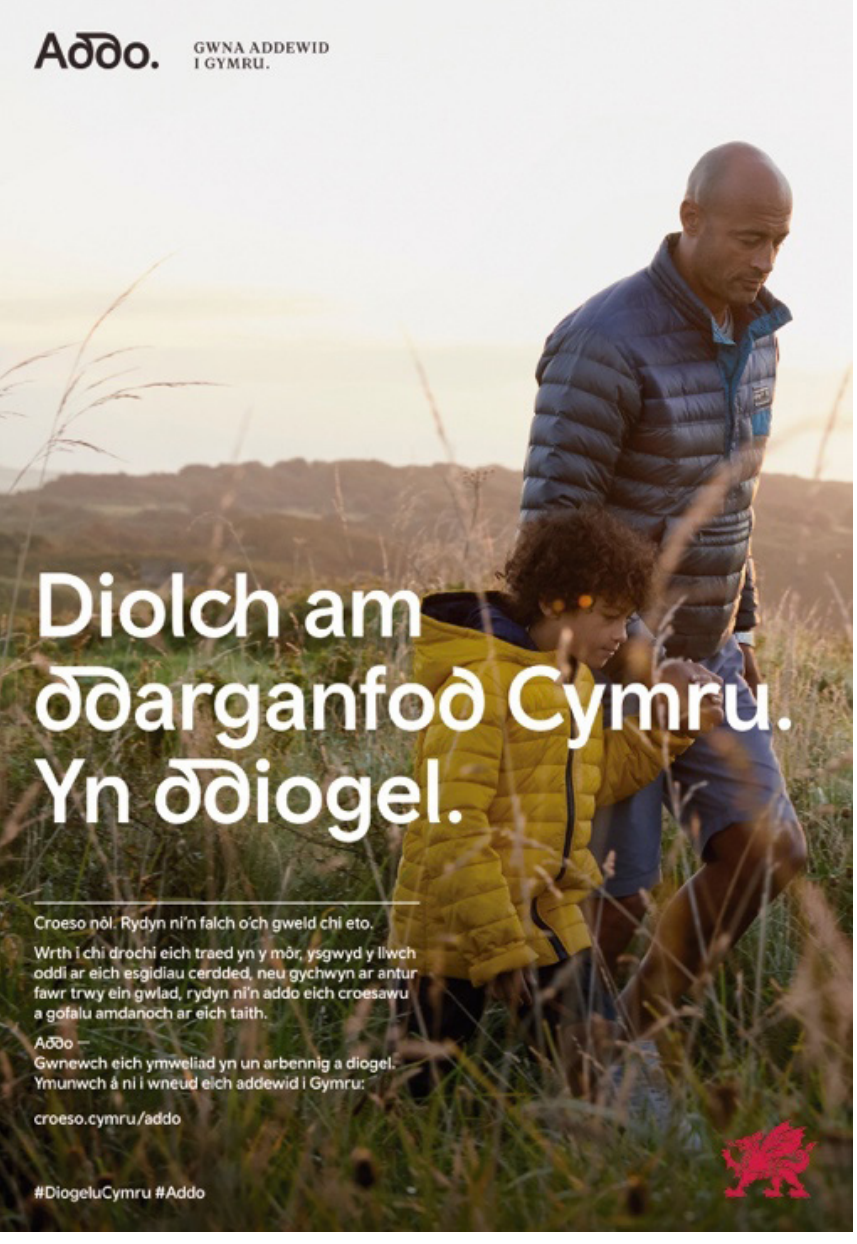

Figura 24.

Ejemplo de aplicación de marca. Portal de marca https://assets.wales.com
Figura 23.

Tipografía Cymru Wales.

Fundición Colophon Typefoundry.

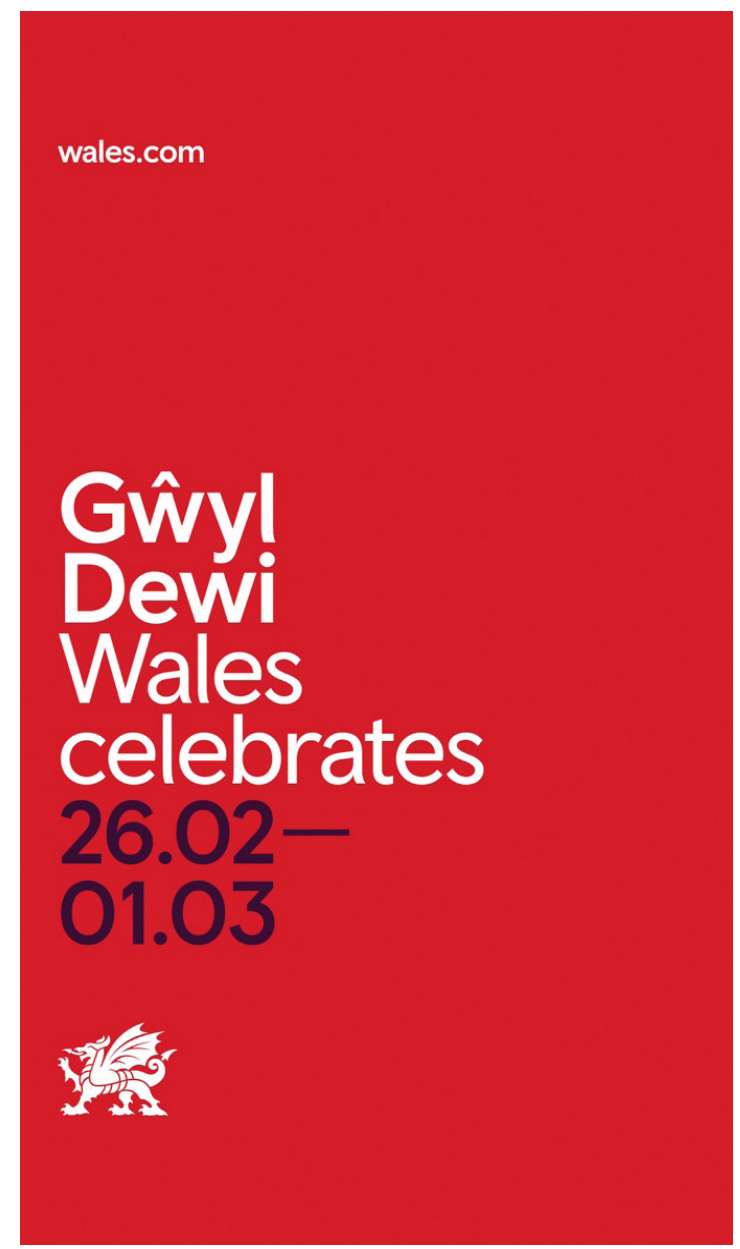

Figura 25.

Aplicación cartel de la marca. 
El Cymraeg (galés) es una de las lenguas vivas más antiguas de Europa y en 2019 el porcentaje de hablantes era casi del $30 \%$ de la población de País de Gales. Es una lengua británica de la familia de las lenguas celtas. Aunque tiene sus raíces en el alfabeto latino, el galés escrito omite ciertos caracteres como la «j», «k», «q», "v», "X», «Z». Comprende 29 caracteres con la inclusión de 8 dígrafos o combinaciones de letras. La creación de la familia tipográfica corrió a cargo de la fundición Colophon Typefoundry ${ }^{21}$, y toma señas de identidad del patrimonio tipográfico galés que aparece en el Libro negro de Carmanthen o el Libro rojo de Hergest. Sus dígrafos propios son parte esencial de su diseño y son tratados como ligaduras. Gracias al lenguaje de programación OpenType es posible la combinación de los idiomas galés e inglés junto con diferentes gestos visuales dentro de la misma tipografía. Así las combinaciones de los dígrafos "Ch», «ch», "dd" "Ff», "ff», "Ll», "Th» y "th» marcan el tono de la tipografía. Además, toman claves formales de las tipografías celtas y gaélicas para darle a las letras «d», «h», «l», «m», «n», «u» unas curvaturas poco convencionales. Con ayuda de un profesor de galés se revivió una variante medieval de la letra "V» omitida en la actualidad.

Inicialmente se diseñaron dos versiones de palo seco, la Cymru Sans, cuyas formas dan preferencia al idioma galés y la Wales Sans con preferencia por el idioma inglés. Cada una de ellas posee los estilos Body Light, Body Regular, Body Medium, Headline Light, Headline Regular con sus correspondientes itálicas. Más tarde se diseñó la familia con remates Wales Serif ante la evidencia de la necesidad de variantes para crear una jerarquía y riqueza tipográfica y solventar todas las necesidades de comunicación de la identidad visual. Para la empresa de transportes Transport for Wales se creó la versión Cymru Sans Transport, una palo seco estarcida de caja alta basada en Cymru Wales Sans. En la creación de este proyecto ha tenido una especial relevancia los avances en los formatos digitales de la tipografía y su programación. La aparición en 1996 del formato de fuentes OpenType ${ }^{22}$ ha permitido entre otros avances técnicos la inclusión en un mismo archivo de fuentes de todos los idiomas que necesitemos, superando las limitaciones de los anteriores formatos Postcript y True Type. Además, desde 2011 existen los formatos de webfonts que han superado las limitaciones del diseño web en cuestiones de tipografía, lo que ha sido un salto de calidad y coherencia gráfica en la unificación de todos los soportes de una marca. Un mismo diseño de tipografía puede estar disponible hoy en día para todos los soportes tanto digitales como físicos. Las técnicas de hinting ${ }^{23}$ han permitido también optimizar aquellas fuentes destinadas específicamente al soporte pantalla en función de las necesidades de la institución. El formato OpenType también permite la creación de alternativas estilísticas en una misma fuente, ofreciendo diferentes variantes

\section{1. https://www.colophon-foundry.org/custom/wales/}

22. OpenType es un formato de tipografía creado por Microsoft y Adobe en 1996 para proporcionar a los usuarios un conjunto de herramientas tipográficas avanzadas. Basado en Unicode, además de ser una tecnología multiplataforma permite un conjunto de caracteres de hasta 65.535 glifos, lo que le permite en un solo archivo admitir todos los idiomas globales además de funciones tipográficas avanzadas como los caracteres alternativos, ligaduras, estilos de números, fracciones, ornamentos, versalitas etc...

23. El término hinting se usa para definir al conjunto de instrucciones de una tipografía digital que permite una óptima visualización en pantalla y en tamaños pequeños a través de la modificación puntual de las curvas vectoriales para adaptarse a la cuadrícula de pixels. 
en el diseño que van desde los tamaños ópticos ${ }^{24}$ muy usados en diseño editorial hasta alternativas contextuales para variar el diseño en función de las necesidades concretas del idioma, como es el caso. Estas investigaciones históricas han permitido crear una tipografía versátil y que atiende al bilingüismo, aumentando el valor de su identificación territorial y con la que el gobierno espera ayudar a aumentar el uso del idioma galés entre su población.

\section{Conclusiones}

Observando los ejemplos analizados, la tipografía creada a medida como parte esencial de la identidad de los países se ha convertido desde comienzo del siglo XXI en una herramienta de creación de marcas identitarias. Estos proyectos presentan una especial relevancia al identificarse con el patrimonio local y su historia, como estrategia para proyectarse hacia el resto del mundo. La función identificadora de la tipografía se presenta aquí como posible remedio al contexto global que diluye la diversidad y en el que no es fácil destacar. La exaltación de lo propio es una estrategia que muchos países buscan como arma para luchar contra la homogeneización en la que vivimos, con las ciudades y barrios plagados de multinacionales que los convierten en similares e intercambiables. Una apuesta por la tipografía que surge de lo local, de las tradiciones y su patrimonio cultural y de lo vernacular supone una diferenciación para posicionarse como país en el mundo con respecto a tus vecinos.

También observamos cómo la identificación emocional del ciudadano con lo propio es un sentimiento muy relevante en la construcción de una identidad visual de país. En todas las identidades analizadas aquí vemos como existe una idea simple, perceptible y diferenciada sobre la que se construye la marca y todo su complejo sistema de elementos gráficos y audiovisuales. Entre estos elementos se ha posicionado con fuerza la tipografía, que ha demostrado una importante capacidad de vinculación emocional y cultural con los habitantes, aunque sea de manera sutil e inconsciente. Como tantas otras expresiones visuales la tipografía funciona a muchos niveles, desde la pura transmisión de mensajes textuales, atendiendo a cuestiones de legibilidad y accesibilidad, a las cuestiones identitarias en las que la emoción es un asunto clave.

Dentro de los ejemplos de países analizados se observan diferencias, especialmente en aquellos como Alemania u Holanda, con una gran tradición de diseño de tipografías dentro del campo de la imprenta, y otros como los países nórdicos sin una tradición tan ortodoxa. Mientras que en los primeros los resultados son la creación de tipografías sutiles, funcionales y accesibles, con una base claramente orientada hacia la tradición de la escritura manual, los segundos han tenido que hacer un esfuerzo de reinvención, mirando hacia el pasado, a lo vernáculo, y poniendo en valor figuras de su diseño tipográfico que han seguido planteamientos diferentes alejados de los centros de influencia. En estos pesan más disciplinas como la arquitectura, la artesanía, el dibujo o la pintura que el propio diseño tipográfico, pero paradójicamente han conseguido plantear nuevas ideas y un nuevo lenguaje tipográfico renovado con resultados sorprendentes.

\footnotetext{
24. Véase: Ahrens, Tim y Mugikura, Shoko. (2017). Size-especific adjustments to type design. An
} investigation of the principales guiding the design of optical sizes. Just another foundry.
La tipografía creada a medida como parte esencial de la identidad de los países se ha convertido desde el comienzo del siglo XXI en una herramienta de creación de marcas identitarias. 
La tendencia de creación de tipografías personalizadas para la identidad corporativa es la culminación de un proceso que comenzó con la digitalización y la democratización del diseño en los años 80. A diferencia de la época posmoderna, en la que la experimentación formal era la norma y la calidad disminuyó sensiblemente, hoy en día el nivel de detalle, perfección y versatilidad que puede llegar a alcanzar un proyecto de diseño de tipografía a medida, con amplias familias, variantes size especific, optimización para soportes digitales, formatos, lenguajes soportados etc... han convertido la tipografía en una herramienta muy potente a la vez que asequible para las grandes corporaciones.

Las cuestiones más técnicas también han adquirido una relevancia fundamental. La enorme cantidad de soportes de comunicación que debe atender la identidad de un gobierno demanda unas necesidades técnicas en una tipografía que pueden ser definidas y ampliadas en un proyecto a medida. La apertura hacia el exterior para atender a cuestiones de promoción turística y captación de inversiones requiere una cobertura de idiomas más amplio de lo habitual.

Los aspectos económicos también juegan un papel clave en la decisión de los gobiernos de crear tipografías personalizadas. Aunque pueda parecer lo contrario, en encargo de una tipografía propia para una gran institución supone un importante ahorro de costes. Hay que tener en cuenta que gestionar la imagen gráfica de un gobierno implica el pago de licencias tipográficas tanto de aquellas que son instaladas en los ordenadores de la institución como para aquellas que son usadas en la web y en las aplicaciones interactivas. Especialmente las licencias de webfonts suelen implicar un gasto muy elevado al estar su coste vinculado al número de visitas de usuarios online, algo que en los portales gubernamentales y diferentes webs estatales es elevado. De esta manera, la decisión de la creación de una tipografía personalizada implica un gasto que, si bien inicialmente puede resultar elevado, el ahorro en licencias resulta fácilmente recuperable, al disponer de todas las licencias propias y poder ser usada en cualquier medio.

Una tipografía personalizada, tal y como hemos visto, permite unificar las diferentes aplicaciones de la marca tanto en medios digitales como analógicos. Permite además unificar submarcas, algo fundamental en los gobiernos con múltiples ministerios y áreas. Pero aquello que aporta más valor al diseño en esta estrategia de creación de tipografías a medida es la capacidad de crear una identidad exclusiva, adaptada a aquellos valores que se quieren transmitir, tradiciones, costumbres, idiosincrasias y estrategias de cara al exterior, en definitiva, aportar también con la tipografía aquellos valores que antes se encargaban a los símbolos y signos de la identidad. En el futuro todo indica que la tendencia a la creación de tipografías personalizadas, impulsada por los avances y también por las necesidades tecnológicas y por la cada vez más amplia formación de los diseñadores en estas cuestiones, ira en aumento. Quedaría por dilucidar si los vaivenes del diseño en un futuro irán en la dirección de la personalización o la estandarización.

\section{Referencias}

Ahrens, T., \& Mugikura, S. (2014) Size-especific adjustments to type design. An investigation of the principales guiding the design of optical sizes. Just another foundry. 
Brändle, C., Gimmi, K., Junod, B., Richter, B., \& Museum für Gestaltung Zürich. (2014). 100 Years of Swiss Graphic Design. Prestel Pub.

Middendorp, J. (2018). Dutch Type (reprint). Druk Editions.

Cerezo, J. M. Diseñadores en la nebulosa. El diseño gráfico en la era digital. Editorial Campgràfic.

Chaves, N. (2002). La Imagen Corporativa: Teoría y Metodología de La Identificación Institucional. Editorial Gustavo Gili.

Chaves, N. (2021). Marca Gráfica corporativa, institucional y de lugar. Ed. Experimenta Libros

De Rauly, A. D., Wlassikoff, M., de Rauly, A. D., \& Renner, P. (2011). Futura. Une gloire typographique. Ed. Norma.

Dopico, M. (2020). Tipografía, territorio e identidad. La identidad pública a través de la tipografía personalizada. Recuperado en julio 2021, de Asociación Galega de Deseño. https://dag.gal/es/tipografia-territorio-identidad/

Dopico, M. (2020). Tipografía, territorio e identidad. Construcción de la identidad pública de gobiernos, instituciones y territorios a través de la tipografía personalizada. III Simposio FHD. To be or not to be. El papel del diseño en la construcción de identidades. Barcelona: Fundación Historia del Diseño

Ejlers, S.(1997). Architects in danish graphic design. Scandinavian Journal of Design History, Vol. 7.

García-Garrido. S. (2021). Diseño de la identidad visual de las instituciones. Experimenta Libros.

García-Garrido. S. (2021a). Diseño de comunicación corporativa. Experimenta Libros.

Halén, W., \& Wickman, K. (2004). Diseño escandinavo: Más allá del mito. 50 años de diseño escandinavo en los países nórdicos. Fundación Barrié de la Maza

Hollis, R. (2006). Swiss Graphic Design: The Origins and Growth of an International Style, 1920-1965. Yale Univ Pr.

Huber, J., \& Wenzel, M. (2011). Bundessans and Bundesserif. Truly democratic typefaces. Recuperado en marzo 2021, de I love typpography. https://ilovetypography. com/2014/07/12/bundessans-and-bundesserif-truly-democratic-typefaces/

Hustwit, G. (Director). (2007). Helvetica Film. [Película; vídeo online]. Swiss Dots Veer.

Juárez, L., Blasco, F., \& Blázquez, J. (2015). La marca país como factor clave del turismo. Revisión de las escalas de medición. TURYDES: Revista sobre Turismo y Desarrollo local sostenible, 8(19).

Lommen, M., \& Verheul, P. (2008). Letterrijk Rijksoverheid. De Buitenkant [distr.].

Meyer Andersen, K. (2001) The Crowning touch. National identity in a changing world. Visual identity for danish state institutions by Kontrapunkt Copenhagen. DDD Gallery.

Molenkamp, M., Versteegh, M., \& Bavelaar, H. (2010). The Style of the State. The visual identity of the Dutch government. Ministry of General Affairs. Idea books.

Olins, W. (2006). Brand. Wally Olins on Brands: Las Marcas Segun Wally Olins / Wally Olins on Brands (Tra ed.). Turner. 
INVESTIGACIÓN / Marcos Dopico Castro

Satué, E. (2000). Signos del siglo. MNCARS Museo Nacional Centro de Arte Reina Sofía. DDI, Sociedad Estatal para el Desarrollo del Diseño y la Innovación.

Söderhavet (2014a). The face of a nation. Recuperado en marzo de 2021. https:// soderhavet.com/work/sweden/

Söderhavet (2014b). Sweden Sans, the «Lagom» typeface. Recuperado en marzo de 2021. https://soderhavet.com/news/sweden-sans-the-lagom-typeface/ 